\title{
Plasma-thermal electric furnace for gasification of carbon-containing waste
}

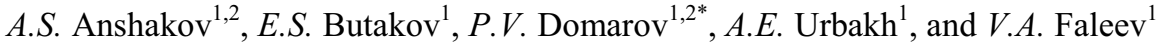 \\ ${ }^{1}$ Kutateladze Institute of Thermophysics SB RAS, Novosibirsk, Russia \\ ${ }^{2}$ Novosibirsk State Technical University, Novosibirsk, Russia
}

\begin{abstract}
The plasma-thermal electric furnace for gasification of various carbonaceous wastes (domestic, biological, agricultural, and other organic waste) has been created for the first time. Its constituent parts are: hydraulic drive for supplying the packed waste into the reaction zone; gas burner with the thermal power of $42 \mathrm{~kW}$; electric-arc plasmatron with a power of $50 \mathrm{~kW}$; chamber for ash residue melting. The test operation of the electric furnace showed that plasma gasification of carbon-containing materials produces synthesis gas suitable for the needs of heat and electric power industry. The results of thermodynamic calculations are in satisfactory agreement with the experimental data.
\end{abstract}

According to the data of [1], the volume of carbon-containing (organic) wastes is significant. In the world, their annual quantity is over 3 billion tons of solid waste and up to $700 \mathrm{~km}^{3}$ of liquid domestic waste and industrial effluents. In the developed countries, from 300 to 750 kilograms of communal and from 1000 to 2500 kilograms of industrial waste are generated per capita per year.

The increasing volumes of waste lead to the search for the new, more efficient ways of their processing. The thermal methods of processing come to replace the open landfills and earth fills, whose exploitation causes environmental pollution; these ways are incineration; pyrolysis; and gasification.

Combustion is one of the main methods of eliminating waste in the world, since it contains a large amount of organic fuel. Since the process of waste combustion occurs at the temperature of $800-900^{\circ} \mathrm{C}$, the exhaust gases include the substances poisoning the atmosphere (dioxins, furans), high molecular toxic compounds, etc.

Currently, waste recycling/utilization by plasma technology is one of the safest ways. All over the world, there are only a few small plants testing the plasma technology, whose main disadvantage is insignificant resource of plasmatron electrodes (up to $100 \mathrm{~h}$ ). In Russia, the plasma plants are not used for waste disposal. In Russia, there are the single experimental samples of plasma plants for processing waste with various degrees of hazard.

The use of plasma technology [2-5] in application to organic waste processing allows the following: reducing significantly the volume of gas that is subjected to purification; melting and vitrifying the inorganic fraction of waste in the reactor (to obtain an inert slag that can be used in construction); excluding formation of nitrogen oxides due to the

* Corresponding author: Domaroff@yandex.ru 
reducing medium in the reactor; obtaining the synthesis gas with calorific value of up to 10 $\mathrm{MJ} / \mathrm{m}^{3}$, suitable for its subsequent use in power generating devices. The technology is based on high-temperature $\left(1200 \div 1600^{\circ} \mathrm{C}\right)$ plasma action and complete decomposition of highmolecular organic compounds and gasification of recyclable products using the arc plasma to produce a useful product: synthesis gas, which is a mixture of hydrogen and carbon monoxide, and inert slag, which can be used as a building material.

A schematic diagram of the experimental plasma-thermal setup with the capacity of up to $20 \mathrm{~kg} / \mathrm{h}$, designed to adjust the technology for high-temperature (plasma) recycling of renewable carbon-containing wastes of various origins (sawdust, rags, polyethylene), is shown in Fig. 1. Based on the results of testing the pilot plant, recommendations for the construction of pilot and industrial plants for processing the organic materials and waste and solving the environmental and energy problems will be developed.

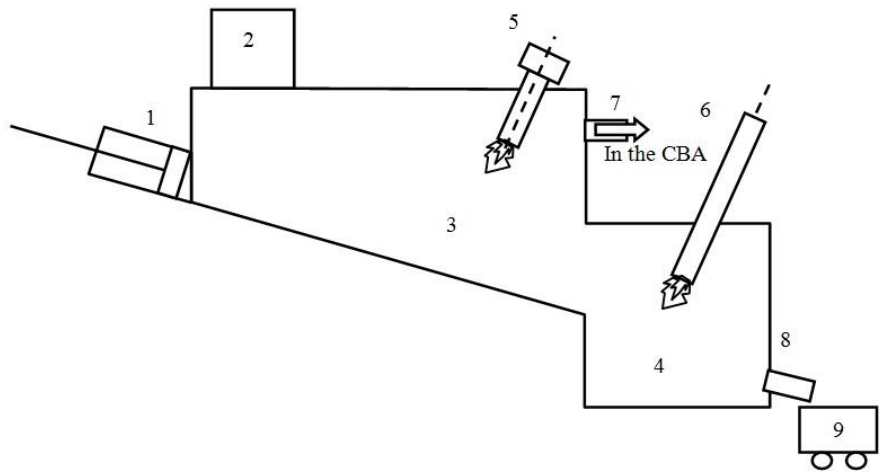

Fig. 1. Scheme of electric-plasma furnace.

Carbonaceous wastes with a bulk weight of $150-200 \mathrm{~kg} / \mathrm{m}^{3}$ are delivered in the boxes with overall dimensions of $200 * 200 * 250 \mathrm{~mm}$ and are fed into the working space of the furnace through loading device 2 . The loading device is equipped with a lock chamber, which prevents the escape of flue gases into the atmosphere from the working chamber of the plasma furnace at an excess pressure and suction of the atmospheric air into the working chamber, when it is vacuumized. The waste moves along the inclined sole in gasification zone 3 by means of hydraulic pusher 1 connected to the oil station and the control unit. Preheating of the lining and gasification zone is performed by gas burner 5 with the power of $42 \mathrm{~kW}$ and plasmatron 6 with the power of $50 \mathrm{~kW}$. Then, the temperature of $1200^{\circ} \mathrm{C}$ at gasification is maintained only by the plasmatron. The mean mass temperature of the air plasma flowing from the plasmatron is $4000 \mathrm{~K}$. The synthesis gas obtained in the zone of gasification (fuel gas) is fed to a centrifugal-bubbling apparatus (CBA) for quenching the plasma chemical reactions and dust removal. The ash residue formed by waste gasification, which contains the unburned particles and carbon residue, falls into combustion zone 4 (Fig. 1), where carbon is burned under the action of a plasma jet and the mineral part of waste is re-melted into inert slag. After the CBA, the fuel gas is supplied to the after-burner chamber, where it burns down to $\mathrm{CO}_{2}$. Before the release into the atmosphere, the gas passes into the mixer for subsequent cooling by mixing with the required amount of atmospheric air.

The source of energy for gasification of the organic part and melting the inorganic part is the plasmatron, as well as the chemical energy of carbon oxidation reactions. Oxygen enters the furnace through the plasmatron with plasma-forming gas. The slag is periodically poured off through tap hole 8 into trolley 9.

Furnace lining has the fire-resistant and heat-insulating layers made of chamotte and mullite-siliceous bricks; the chamber fastenings and vaults are made of heat-resistant 
concrete. On the lateral walls of gasification chamber, there are the nozzles for air supply, viewing window, and hatch for inspecting the lining. In the upper part of gasification chamber, there is a pipe branch for synthesis gas removal from the furnace; on this pipe branch, there is a device for sampling gases for analytical control.

The operating parameters of the electric furnace are determined by stable operation of its constituent elements. The plasmatron is the main of them. The results of its experimental characteristics are presented below.

To maintain a high temperature in the furnace chamber, an electric arc plasmatron is used. The trouble-free operation of setup required reliable long-term operation of the plasmatron. In this connection, the plasmatron with the power of $50 \mathrm{~kW}$ was designed, manufactured, and tested out with different flow rates of plasma-forming air $(3 \div 6) \bullet 10^{-3} \mathrm{~kg} / \mathrm{s}$ with current varying from $120 \mathrm{~A}$ to $200 \mathrm{~A}$.

The current-voltage characteristic of the arc is the most important electrophysical and energy characteristic of the arc plasmatron. It determines the region of stable arc burning at a change in the determining parameters: current strength, flow and type of plasma-forming gas, pressure of the medium, and geometric dimensions of plasmatron discharge chamber. The parameters of power supply source that ensure reliable continuous operation of the plasmatron are determined by the shape of the current-voltage characteristic and level of attainable voltage and current strength of the arc.

The experimental voltage-current characteristics of arc are shown in Fig. 2 depending on the flow rate of plasma-forming gas.

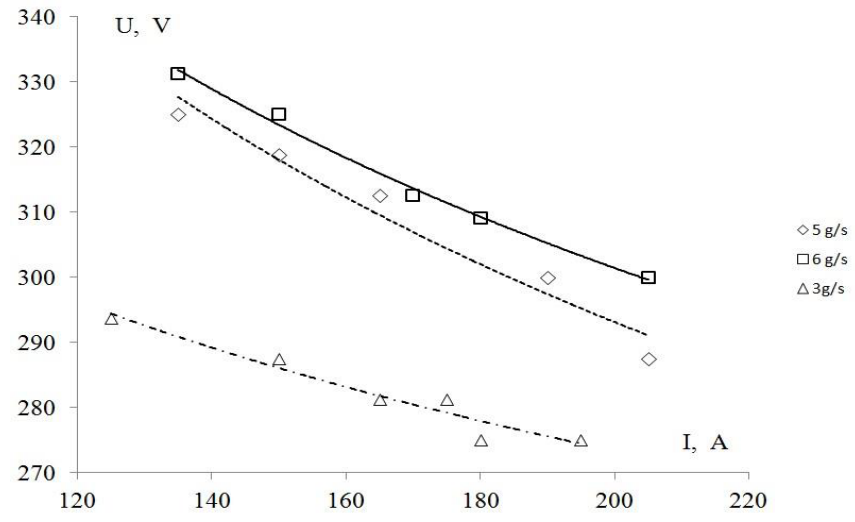

Fig. 2. Voltage-current characteristics of plasmatron arc.

One of the main parameters that determine the plasmatron efficiency is its thermal efficiency. In electric arc plasma generators, the electrodes perceive heat from arc radiation, convective heat exchange between arc discharge, plasma-forming gas and electrode walls, conductive heat transfer, and, finally, the cathode and anode arc spots. Heat from the outside of electrodes is removed with cooling water. Plasmatron efficiency is determined by the measured heat fluxes. At that, the integral heat fluxes entering the electrodes and other water-cooled elements of the structure are determined without dividing them into components. The method of heat flux measuring is standard: it is necessary to know the flow rate and temperature drop of water at the inlet and outlet of plasmatron.

The obtained experimental data are shown in Fig. 3. As it can be seen, the value of thermal efficiency at the certain low airflows is about $80 \%$. 


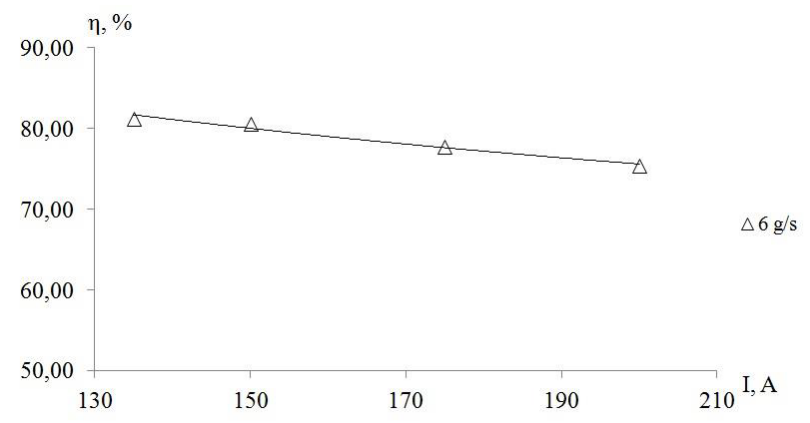

Fig. 3. Thermal efficiency of plasmatron depending on arc current.

Thermodynamic calculations of the process of gasification of model waste in the form of polyethylene pellets, textiles and sawdust were carried out, when the oxidizing gas in the amount stoichiometric for gasification, was fed into the reaction zone. These calculations were aimed at the following experimental studies of the plasma furnace and electric-plasma technology in general. According to investigation results, it was obtained that the synthesis gas in the volume from 3 to $6.75 \mathrm{~nm}^{3}$ and caloricity from 6 to $12 \mathrm{MJ} / \mathrm{m}^{3}$ is produced per 1 $\mathrm{kg}$ of polyethylene production waste depending on the oxidizing gas (air, steam, oxygen). The synthesis gas in the volume from 1.22 to $1.5 \mathrm{~nm}^{3}$ with calorific value from 9 to 11.5 $\mathrm{MJ} / \mathrm{m}^{3}$ is produced per $1 \mathrm{~kg}$ of textile waste depending on the oxidizing gas (air, steam, oxygen). The synthesis gas in the volume from 0.9 to $1.6 \mathrm{~nm}^{3}$ with calorific value from 7 to $11.5 \mathrm{MJ} / \mathrm{m}^{3}$ is obtained per $1 \mathrm{~kg}$ of sawdust depending on the oxidizing gas (air, steam, oxygen).

\section{Conclusions}

1. A plasma-thermal electric furnace for gasification of carbonaceous wastes with productivity of up to $20 \mathrm{~kg} / \mathrm{h}$ was developed, made and tested for the first time.

2. Experimental studies of electric-arc plasmatron showed the possibility of continuous operation of its electrodes during 500 hours and longer.

The work was financially supported by the Ministry of Education and Science of the Russian Federation according to the Subsidiary Agreement No.14.607.21.0118 (unique project identifier RFMEFI60715X0118)

\section{References}

1. V. Lotosh, Processing the waste of environmental management (Yekaterinburg: Poligrafist 2007)

2. A. Anshakov, V. Faleev, A. Danilenko, et al, Thermophys. and Aeromech., 14, 607 (2007)

3. A. Anshakov, A. Valiliev, A. Pinaev, V. Faleev, Thermophys. and Aeromech., 17(4), $595(2010)$

4. A. Bratsev, V. Kuznetsov, V. Popov, A. Ufimtsev, High. Temp., 49, 244 (2011)

5. V. Messerle, A. Mosse, A. Ustimenko, Thermophys. and Aeromech., 23, 637 (2016) 